\title{
Una revisión acerca del estudio de la movilización de la protesta y la organización de los movimientos sociales a partir de las teorías de la acción colectiva
}

Hernán Camarero ${ }^{1 *}$

Tipo de trabajo: Artículo

Material original autorizado para su primera publicación en el Journal de Ciencias Sociales de la Facultad de Ciencias Sociales de la Universidad de Palermo

Recibido 10-10-2012

Aceptado 24-11-2012

\section{Resumen:}

El objetivo de este artículo es el de realizar un análisis de carácter conceptual acerca de los modos en que los movimientos sociales fueron examinados por la sociología y las teorías de la acción colectiva. Se atiende, especialmente, a las diferentes formas en que fue abordado el examen de la movilización y la organización de la protesta. La existencia de una asociación directa entre las tensiones estructurales en una sociedad y la movilización de la protesta fue una idea que tuvo vigencia durante muchos años en la teoría sociológica. En el texto se problematiza sobre esta afirmación, trazando el itinerario histórico que esta disciplina recorrió en torno al tema. En la teoría sociológica se pueden reconocer varios momentos interpretativos a propósito de cuándo, cómo y por qué se produce la movilización de la protesta. Se indaga cada uno de ellos, estudiando cómo se fue procesando aquella idea, y de qué modo fue cuestionada por aportes posteriores. La conclusión es que, frente a las primeras interpretaciones, se fue avanzando con un modelo multifactorial que hilvanó los siguientes pasos analíticos: a) tensiones; b) malestar, disidencia, descontento y privación; c) recursos internos (redes, organización) y recursos externos (oportunidades políticas); d) acción colectiva (movilización de la protesta).

Palabras clave: Protesta - Movilización - Movimientos sociales - Acción colectiva

\section{A REVISION OF THE STUDY OF THE PROTEST AND THE ORGANIZATION OF SOCIAL MOVEMENTS FROM THE COLLECTIVE ACTION THEORY}

\begin{abstract}
:
The aim of this paper is to perform a conceptual analysis about the ways that social movements were examined by sociology and theories of collective action. It caters especially to the different ways in which the exam was approached mobilizing and organizing the protest. The existence of a direct association between the structural tensions in society and mobilizing the protest was an idea that
\end{abstract}

$1^{*}$ Doctor y Magister en Historia (UBA). Profesor Universidad de Palermo. Investigador independiente del CONICET / UBA.

E-mail: hercamarero@gmail.com 
has endured for many years in sociological theory. The text problems this claim, tracing the historical journey that this discipline toured around the issue. In sociological theory can recognize several interpretive moments about when, how and why it occurs mobilizing protest. We explore each of them, considering how it was processed that idea, and how it was challenged by subsequent contributions. The conclusion is that, given the first performances, went ahead with a multifactor model that he put together the following analytical steps: a) tension b) discomfort, dissent, discontent and deprivation; c) internal resources (networks, organization) and resources external (political opportunities); d) collective action (mobilization of protest).

Keywords: Protest - Mobilization - Social movements - Collective Action

\section{Introducción}

Desde hace más de tres décadas se está reflexionando, en el campo de las Ciencias Sociales, acerca de la existencia de "nuevos" movimientos sociales. Podemos entender a éstos, adoptando una definición operativa, como aquellos colectivos que no encuentran representación en los partidos políticos o grupos de interés, que actúan al margen de la acción política formal y que por lo tanto representan un reto a las autoridades (Bonamusa Miralles, 1994). ${ }^{2}$ Las características y orígenes de estos movimientos han sido muy variados, pues tendieron a articularse en torno a las más diversas temáticas: pacifistas, ecologistas, feministas, de la defensa de los derechos civiles o los representativos de las minorías sexuales, étnicas o raciales. Claus Offe (1988 y 1992) supo identificar el carácter novedoso de estos movimientos en cuatro aspectos: 1) a diferencia de los surgidos en la posguerra (entre las décadas del 1950 y 1970), ellos ni se han creado ni dependieron de los recursos de los partidos políticos establecidos y de sus políticas electorales; 2) perduraron como fenómenos políticos y continuaron exigiendo un papel en la generación y el uso del poder político, sin refugiarse en manifestaciones literarias, artísticas o religiosas; 3) representaron una crítica o protesta social no reaccionaria, universalista de la modernidad, a través del desafío a los modelos institucionalizados de racionalidad técnica, económica, política y cultural, sin recurrir a la idealización de las instituciones tradicionales y de acuerdos convencionales (familia, valores religiosos, propiedad, autoridad del Estado o la Nación); 4) carecieron de una utopía positiva, una visión amplia o un diseño institucional para una "nueva sociedad" o un nuevo "modelo de producción".

El objetivo de este trabajo es el de realizar un análisis de carácter conceptual acerca de los modos en que los movimientos sociales fueron examinados por la disciplina sociológica y las teorías de la acción colectiva, atendiendo especialmente a las diferentes formas en que fue abordado el examen de la movilización y la organización de la protesta. La existencia de una asociación directa entre las tensiones estructurales en una sociedad y la movilización de la protesta fue una idea que tuvo vigencia durante muchos años en la teoría sociológica. Decidimos problematizar sobre esta afirmación a partir del trazado del itinerario histórico que esta disciplina recorrió en torno al tema. En la teoría sociológica es posible encontrar varios momentos interpretativos a propósito de cuándo, cómo y por qué se produce la movilización de la protesta. Analizaremos cada uno de ellos,

\footnotetext{
${ }^{2}$ Una reflexión acerca del alcance y uso del concepto de movimiento social: Melucci (1988); Raschke (1994); Revilla Blanco (1994).
} 
observando cómo se fue procesando aquella idea, y de qué modo fue cuestionada por aportes posteriores.

La asociación entre las tensiones estructurales en una sociedad y la movilización de la protesta

Es necesario comenzar remontándose a las reflexiones psicosociológicas de los franceses Gustav Le Bon y Gabriel Tarde, formuladas a fines del siglo XIX. Éstas tenían como punto de referencia implícito las movilizaciones multitudinarias de la Revolución francesa. Para Le Bon (2005), en Psicología de las masas, originalmente publicado en 1895, estos comportamientos colectivos se oponían radicalmente a las formas habituales y racionales de actuación de los individuos aislados. Siendo parte de una muchedumbre, las facultades racionales, el juicio moral y la personalidad consciente de un individuo desaparecían, víctimas del contagio y la sugestión de un líder. Era la muchedumbre la que adquiría una "unidad mental", caracterizada por la credulidad y la exageración de los sentimientos. Con la pérdida de los controles de la racionalidad, la multitud quedaba en manos de la turba y de los desechos de la sociedad. Para Tarde, incluso en las asambleas electorales sometidas a la influencia de un líder se producía una notable intensificación de las emociones no controladas por el raciocinio, que conducían al triunfo del odio y del fanatismo de las masas. ${ }^{3}$ En las visiones de Le Bon y Tarde se diferenciaban los comportamientos de los individuos aislados de los colectivos: si los primeros se caracterizaban por la adopción de decisiones racionales de acuerdo con sus intereses, respetando las normas sociales, los segundos se definían por la irracionalidad propia de las multitudes, producto del contagio emocional, y por la decisión de saltar por encima de toda regla social.

Tiempo después, en las décadas de 1950 y 1960, los análisis de las teorías sobre la sociedad de masas volvieron a instalar el interés por las características de los participantes en las acciones de protesta. En esta dirección, William Kornhauser (1959) llegaba a un diagnóstico pesimista sobre la capacidad de comportamiento autónomo de los individuos, pues encontraba una sociedad definida por el aislamiento de éstos, la ausencia de grupos independientes y la centralización de las decisiones, con el consiguiente desarrollo de organizaciones burocráticas que obraban a expensas de las asociaciones intermedias. De esta manera, los miembros del conjunto social que no forman parte de las elites, es decir, las masas, resultaban fácilmente movilizables por las elites. En ausencia de formas de integración y solidaridad (grupos independientes, comunidades locales o asociaciones voluntarias), los individuos alienados y desarraigados se sentirían atraídos por los llamamientos de organizaciones extremistas y antidemocráticas. Así, en la atomización social, y en los sentimientos de alienación generados por ella, estarían las causas del estallido de movimientos de protesta y de la participación en ellos de quienes deseaban superar el aislamiento y la ansiedad. Como podemos observar, en las teorías hasta aquí enunciadas había una explicación lineal entre las movilizaciones y las causas que las provocarían.

Hacia la misma época comenzaba a ponerse en boga, especialmente en Estados Unidos, el estructural-funcionalismo, que instaló en el primer plano de análisis las tensiones estructurales,

\footnotetext{
${ }^{3}$ En la obra de Tarde pueden verse variaciones en sus concepciones sobre el comportamiento de las masas. Es interesante, en ese sentido, confrontar Monadología y sociología (2006), escrita en 1893, con L'opinion et la foule, de 1901. Un análisis de la obra de Tarde y de Le Bon, en Oberschall (1973).
} 
por ejemplo, las mutaciones económicas o los cambios en la población. Concibió a ellas como causantes de las dislocaciones en la sociabilidad y de la aparición de la protesta. Según esta visión, entre la destrucción de la vieja sociedad y el surgimiento de la nueva existía un período de transición en el que actuaban las masas no absorbidas por el nuevo sistema. Así, las movilizaciones no institucionalizadas serían la expresión de un desequilibrio del sistema en donde fallan los mecanismos de integración. ${ }^{4}$ Lo importante a observar en este planteo es que la participación en un movimiento colectivo aparece como una suerte de terapia, en donde se intenta obtener un sentido de identidad o de pertenencia. La idea clave parece ser la de "desarraigo", sobre todo entre los marginales o desamparados del orden social. En este esquema, a largo plazo, la modernización generaría nuevos comportamientos, hábitos e instituciones que reabsorberían las demandas y readaptarían a estas masas. La "acción colectiva" significaría, entonces, cubrir un hueco o superar una dislocación generados en una sociedad sometida a transformaciones estructurales.

Claro está, dentro de esta visión global encontramos varios matices y diferencias interpretativas. Por ejemplo, el planteo acerca de la irracionalidad de las multitudes reapareció parcialmente, varios años después de la obra de Le Bon y Tarde, en la obra de Talcott Parsons (1966). Para el sociólogo norteamericano no existían diferencias conceptuales entre la protesta y otras formas de conducta "desviada", como los delitos o los crímenes. La irracionalidad de la protesta se evidencia en los componentes motivacionales de los disturbios. Temores, esperanzas, ansiedades, fantasías utópicas, idealización de situaciones pasadas: esas eran para Parsons las raíces psicológicas de los actos de protesta. En tanto, Robert K. Merton (1957) matizó la integración de las acciones de protesta en el amplio cajón del "comportamiento desviado", en sus estudios sobre las distintas formas de respuesta a las tensiones a que se ven expuestos los actores sociales como consecuencia del conflicto entre los valores socialmente aceptados y los medios limitados de que dispone para alcanzarlos. Merton distinguió la actitud de quienes están dispuestos a utilizar todo tipo de medios, incluyendo los ilegales o ilegítimos, para conseguir ventajas personales y la de los participantes en movimientos inconformistas, cuya pretensión es cambiar las normas y los valores vigentes en beneficio de la colectividad y no de los propios rebeldes. Serían las acciones de estos últimos (asentadas en nuevos valores) lo que impulsaría el cambio social.

Neil Smelser (1989), si bien siguió colocando en primer plano los componentes irracionales en pos de explicar las creencias colectivas, fue el que aportó un mayor desplazamiento del problema. Alejó su estudio del comportamiento colectivo de los enfoques psicologistas para dedicarse al examen de los determinantes sociales de la protesta. Con él, la indagación se dirigió abiertamente a las tensiones estructurales y las creencias compartidas, en lugar de la sugestión o el contagio (a los que Le Bon y Tarde dieran tanta importancia). Smelser elaboró una secuencia con distintos determinantes del comportamiento colectivo (tal el nombre con el que fue conocido este planteo). Estos incluían: la conductividad estructural, es decir, las condiciones generales que permiten o inhiben ciertos tipos de comportamiento colectivo; las tensiones estructurales, derivadas de los diferentes intereses en conflicto; el surgimiento y difusión de creencias generalizadas, que definen los agravios y señalan los caminos adecuados para remediarlos; la aparición de acontecimientos

\footnotetext{
${ }^{4}$ Fue a partir de esta interpretación, entre otras, desde donde indagó el sociólogo italiano Gino Germani durante su estancia en la Argentina para explicar el surgimiento del peronismo. Era la hipótesis de las "masas en disponibilidad", las cuales, desorientadas por abruptos cambios, no sabrían que hacer con la libertad y la entregarían a otro (un líder populista) para que disponga de ella. Ver: Germani (1962). Para una reconstrucción de estas influencias en la obra del "padre fundador" de la sociología científica en la Argentina: Jorrat \& Sautu (1992); Blanco (2006).
} 
decisivos o precipantes, que dan un contenido inmediato a esas creencias y disparan la acción de los implicados en el movimiento; el desarrollo de grupos coordinados, capaces de suministrar el liderazgo, los recursos económicos o los medios de comunicación que el movimiento necesita, pues sin ellos el malestar acabaría en disturbios ocasionales; y el funcionamiento del control social, o sea, la respuesta al desafío por parte de las autoridades.

Lo que puede advertirse es que las concepciones antes expuestas, en términos generales, tendían a considerar a la estabilidad de la sociedad como un principio. Es decir, ellas presuponían un orden social que se vería cuestionado sólo episódicamente. Se desestimaba, de este modo, que las tensiones sociales suelen ser permanentes, aunque no siempre de ellas deriven movimientos sociales de protesta duraderos. En gran medida esto pudo ser mejor percibido hacia fines de los años '60, en el momento en que comenzaba una nueva oleada de conflicto social en el mundo occidental. Allí fue cuando apareció una nueva formulación teórica sobre el tema, que retomó una tradición de estudios politológicos sobre la violencia colectiva: la de la "privación relativa". Uno de los más firmes defensores de este planteo fue Ted R. Gurr. En esta visión, la privación relativa no podía entenderse como una realidad objetiva, sino como resultado de la percepción de dicha realidad por los propios actores. Las frustraciones de expectativas aparecían como causa de las reacciones colectivas. En este acercamiento al sujeto se evaporaban conceptos anteriormente claves como la pasión o la manipulación. La privación no era un equivalente de la pobreza o la miseria, sino una consecuencia de la disparidad entre las expectativas y las realidades (no sólo relacionadas a los bienes materiales, sino también a la participación política y a las posibilidades de desarrollo individual). Eran muy variadas las formas como podía manifestarse esa disparidad y los sentimientos de privación consiguientes: una privación respecto de las aspiraciones (cuando las aspiraciones de la población aumentan por el contacto con otros sectores más favorecidos, mientras la capacidad para satisfacer esas aspiraciones permanece constante); una privación por decrecimiento (cuando disminuye la capacidad de obtener bienes o valores, mientras las expectativas se mantienen estables); una privación progresiva (cuando tras un período de prosperidad que permitió un aumento de las ganancias y de las expectativas, una crisis lleva a una disminución de dichas ganancias, pero las expectativas mantienen su orientación ascendente). Para Gurr no existía una relación inmediata entre la privación y la protesta (o la violencia), pues muchos consideran que la privación forma parte del orden natural de las cosas o que la acción violenta es inútil y contraproducente. Así, la posibilidad de que estalle una protesta violenta está en función de la intensidad de los sentimientos de privación (o la profundidad del malestar) y las dimensiones del grupo afectado por ese descontento.

La nueva teoría de la privación relativa, dada su complejidad, representó un avance con respecto a las explicaciones anteriores. Sin embargo, su insistencia en los aspectos psicológicos, en contraste con la importancia otorgada por Smelser a los determinantes estructurales, provocó algunos cuestionamientos. En particular, se observó la dificultad de medir los grados de insatisfacción de los distintos actores sociales y se refirió al descuido de los componentes no intencionales de las protestas. Las críticas que recibió esta teoría de la privación relativa fueron variadas. ${ }^{5}$ Una de las más firmes impugnaciones fue la que apuntó acerca de la desestimación completa que habría hecho la nueva teoría de la privación relativa respecto a un elemento clave para explicar la acción colectiva

\footnotetext{
${ }^{5}$ Por ejemplo, Theda Skocpol (1984) cuestionó en este enfoque la carencia de un análisis de las transformaciones estructurales y recordó el carácter impredecible de los fenómenos de protesta o revolución, como consecuencia de situaciones no previstas de antemano en la dominación del Estado y la clase dominante.
} 
de protesta: la organización. El sociólogo norteamericano Barrington Moore (1965) apuntaba que si bien ya era importante detectar que en trasfondo de toda rebelión hay algún tipo de descontento, de lo que se trataba era de explicar el camino que lleva del segundo a la primera. En sus diferentes investigaciones sobre procesos huelguísticos, movimientos sociales y revueltas (especialmente, en Francia e Inglaterra), el también sociólogo, cientista político e historiador norteamericano Charles Tilly, ejerció una crítica global a la teoría de la privación relativa, juzgándola de incompleta, pues pasaría directamente de los estados mentales individuales a los colectivos (Tilly, 1978 y 1995; Shorter y Tilly, 1985; Tilly y Wood, 2009). Lo que señalaba Tilly era que los individuos no se movilizaban por arte de magia para participar en alguna empresa colectiva por muy furiosos o frustrados que pudieran sentirse. Estos sentimientos sólo podrían canalizarse hacia fines colectivos por medio de las funciones coordinadoras y dirigentes de una organización, sea ésta de tipo formal (un sindicato o una sociedad de ayuda mutua) o como una red informal. En la visión de Tilly, la organización era un factor imprescindible para explicar el descontento individual. Sin este "puente", los desgraciados se limitarían a autocompadecerse de forma pasiva sin hacer nada para intentar salir de tal situación.

Muchos de estos replanteos tuvieron que ver con el hecho de que, desde las décadas del '60 y '70, se venían produciendo diversos acontecimientos exteriores a la disciplina sociológica que impactaron profundamente en la forma de estudiar el fenómeno de la acción colectiva de protesta. Los movimientos colectivos de protesta social ya no podían ser entendidos como infrecuentes o episódicos sino que comenzaban a mostrarse bajo una notable perdurabilidad. En Estados Unidos y Europa se consolidaban o surgían nuevos movimientos permanentes por los derechos civiles, pacifistas (contra la guerra de Vietnam), estudiantiles, a favor de la liberación de la mujer (diferenciados del feminismo tradicional), por el derecho al bienestar de las capas más desfavorecidas de la población, ecologistas y antinucleares. A esto se sumaba las extendidas luchas por la independencia de los antiguos territorios coloniales o las primeras revueltas contra los regímenes burocráticos en Europa del Este (Hungría en 1956 y Checoeslovaquia en 1968). Lo novedoso no era sólo la riqueza de experiencias y casos de estudio que emergían por doquier, y que obligaron al replanteo que antes aludíamos, sino que muchos sociólogos e investigadores pudieron tener una observación directa y, frecuentemente, una participación activa en los nuevos movimientos. Fueron precisamente estas vivencias las que condujeron a un malestar creciente con las viejas doctrinas explicativas. Ya no era posible seguir considerando a los participantes de las protestas como entes anómicos e irracionales; por el contrario, éstos aparecían como individuos racionales, integrados a la sociedad, miembros de organizaciones, impulsados a la acción por objetivos concretos, valores generales, intereses articulados y cálculos racionales de estrategia. Todo esto fue lo que condujo a un verdadero cambio de paradigma en el tratamiento del tema.

Por otra parte, el aporte que desde las décadas del '50 y '60 venían haciendo una serie de historiadores sociales, sobre todo los provenientes de la tradición marxista inglesa, fue ejerciendo una notable reconsideración del problema de la acción colectiva. ${ }^{6}$ George Rudé (1971), en sus estudios sobre los movimientos de revuelta popular en Inglaterra y Francia durante los siglos XVIII y XIX, demostró que los participantes de motines y disturbios no tenían necesariamente una carga irracional o violenta per se, ni provenían fundamentalmente de los sectores marginales o manipulables de la sociedad (como los vagabundos), como pensaban Le Bon y Tarde. Eric J. Hobsbawm (1968)

\footnotetext{
${ }^{6}$ Para una reconstrucción global de esta corriente: Kaye (1989).
} 
explicó que los movimientos dotados de organización contaban con mayores posibilidades de éxito que las revueltas de carácter espontáneo. E. P. Thompson (1991), en sus investigaciones sobre los movimientos populares preindustriales, remarcó el contenido racional de sus objetivos y la elección de los blancos contra los que se dirigían los participantes de los motines de subsistencia. Georges Lefebvre (1986) destacó el papel de las redes establecidas de comunicación y los miedos justificados de los campesinos al bandidaje como factores decisivos en el estallido de movimientos de protesta, desacreditando así las explicaciones conspirativas y las que aludían a un "contagio social" irracional como causa de este tipo de acciones.

Pero el enriquecimiento de perspectivas analíticas no sólo provino de esta nueva historia social. Otro aporte novedoso en el examen de la acción colectiva fue el que, desde mediados de la década del '60, encaró Mancur Olson (1965), a partir de los cálculos racionales de costes y beneficios. Era una propuesta que intentaba liberarse de las limitaciones de las teorías psicológicas. Su explicación se dirigía hacia el comportamiento de los miembros de organizaciones o grupos, pero indirectamente sirvió para una indagación de los movimientos sociales. De su visión se extrae la conclusión de que no bastan intereses o agravios comunes para producir una acción colectiva, tal como se creía anteriormente. Analizando la participación de los individuos en los diversos tipos de asociaciones voluntarias, Olson observó que estas organizaciones se orientaban al logro de "bienes colectivos" (cualquier bien de cuyo consumo no se puede excluir a aquellos que no lo pagan). Los problemas de participación surgían desde el momento en que algunos de sus miembros consideran que los costes superan a los posibles beneficios. Esto se agudizaría más en las organizaciones de gran escala, pues dadas las dimensiones del conjunto, cada individuo sabe que sus propios esfuerzos no tendrán un efecto apreciable sobre la situación de su organización y que si se alcanza el objetivo deseado podrá disfrutar de todas las mejoras logradas, haya trabajado o no en su consecución. Además del bien colectivo, en toda organización existen bienes individuales que actúan como "incentivos selectivos" a la hora de estimular la acción de sus miembros (como el prestigio, el respeto ajeno, una posición de liderazgo, la amistad de los demás) y sanciones a quienes se niegan a participar en las tareas colectivas.

En los años '70 se fue erigiendo lo que se dio en llamar la teoría de la Movilización de recursos (a partir de autores como Mayer N. Zald, John D. McCarthy, William Gamson, Anthony Oberschall y Craig Jenkins, entre otros) que complejizó aún más la combinación entre la organización y la movilización para explicar la acción colectiva de protesta. Ya anticipada en los planteos de Charles Tilly, esta teoría supuso un cuestionamiento radical de la afirmación que establecía una asociación directa entre las tensiones estructurales en una sociedad y la movilización de la protesta. Esta nueva teoría puso especial énfasis en las continuidades entre el movimiento social y las actuaciones institucionales, en la racionalidad de los actores de los movimientos y en los problemas estratégicos que enfrentaban. Como los expresó Craig Jenkins (1994), algunos de los presupuestos de este enfoque eran: 1) las actuaciones de los movimientos son respuestas racionales de adaptación a los costos y beneficios de diversas líneas de acción; 2) los objetivos básicos de los movimientos se definen por conflictos de intereses que se construyen como relaciones de poder institucionalizadas; 3) los agravios que dichos conflictos generan son suficientemente ubicuos como para que la movilización dependa de cambios en los recursos, en la organización del grupo y en las oportunidades para la acción colectiva. 
Aquí se introduce con fuerza la idea de los recursos. Estos pueden ser materiales (trabajos, salarios, ahorros, y el derecho a los bienes materiales y servicios) y no materiales (autoridad, compromiso moral, fe, habilidades). Estos recursos se crean constantemente, se intercambian, se consumen, se transfieren y hasta se pierden. El manejo de ellos representaría la esencia de la actividad de los movimientos sociales de protesta. Los líderes del movimiento son los que intermedian los recursos entre el movimiento y la sociedad y los que los distribuyen a modo de incentivos entre sus miembros, introduciendo así un modelo de oferta y demanda aplicado a la afluencia de recursos. Los líderes establecen una racionalidad en el movimiento basada en el costo-recompensa de las acciones de protesta que se ve afectada por la estructura social y por la actividad de las autoridades. Así, los actores del movimiento tendrían una racionalidad económica que les sirve para explotar en beneficio propio los conflictos de intereses construidos dentro de las relaciones de poder institucionales.

El aporte sustancial de la teoría de Movilización de recursos es el reemplazo de la antigua creencia que interpretaba las actividades de protesta como un fenómeno espontáneo y manipulado por los líderes por un énfasis en la interacción organizacional de los distintos participantes. La atención se desplaza de la masa hacia las élites, pues son éstas las responsables para atraer recursos hacia la organización y para canalizar el descontento hacia una acción colectiva. Otro aporte clave de esta teoría es el de haber destacado la importancia capital de la infraestructura organizacional como un recurso básico que permitiría la actividad de protesta de los movimientos sociales, movilizando a sus miembros y transformando los sentimientos difusos del grupo en recursos materiales. La infraestructura organizacional está constituida por cuatro elementos: los miembros (peculiaridad de los individuos que se movilizan); la solidaridad (redes que permiten la participación); las comunicaciones (medios que facilitan la movilización); y liderazgos (reclutados entre los que disponen de recursos excedentes, como tiempo, energía o dinero, y que a pesar de no beneficiarse de la movilización los ponen al servicio de sectores no privilegiados). Así, un movimiento social de protesta se originaría por una afluencia de recursos y una organización del grupo que permitiría movilizar tales recursos.

\section{Los aportes del modelo de Proceso Político}

El modelo de Proceso Político constituyó otro aporte sustancial a la teoría de la acción colectiva en sus estudios sobre la protesta y los movimientos sociales. Fue desarrollado por autores como Michael Lipsky o Peter K. Elsinger, y rescatado por el ya mencionado Charles Tilly o Sidney Tarrow. Esta teoría presta especial consideración a los determinantes estructurales del contexto político para explicar un movimiento de protesta. El examen se orienta hacia las oportunidades y límites que el sistema político ofrece, adquiriendo relevancia como factor explicativo lo que enmarca a la acción colectiva. Es decir, como señala Tarrow (1997: 151), se introduce la problemática del "cuando" en el estallido de la movilización de la protesta. Con este enfoque se abandona la anterior preponderancia por el rol que ejercían los recursos materiales y humanos (la organización) y se privilegia el análisis de la estructura de oportunidad política nacional (que se presenta como siempre cambiante) y su efecto en la propensión de provocar una acción colectiva. Los movimientos sociales de protesta pasan a ser analizados como organizaciones con capacidad de establecer estrategias dentro de 
un contexto político que los determina estructuralmente, tanto en los repertorios de protesta que asumen, como en sus posibilidades de acción y éxito (Bonamusa Miralles, 1994: p. 57).

Desde el análisis de Tarrow podemos sistematizar las ventajas de este modelo de estructura de oportunidades políticas, señalando que la formación de movimientos sociales de protesta es producto de la explotación y creación de dichas oportunidades. Lo que se destaca aquí es la movilización de recursos externos al grupo. Según esta visión, aunque las oportunidades políticas están desigualmente distribuidas (al contrario que los recursos internos como el dinero, el poder o la organización), incluso los grupos débiles y desorganizados pueden sacar partido de ellas. Los cambios más importantes en la estructura de las oportunidades son cuatro: a) la posibilidad del acceso a la participación (grado de apertura del sistema político); b) los cambios en los alineamientos de los gobiernos y las frustraciones del poder electoral; c) la disponibilidad de aliados influyentes; y d) las divisiones entre las élites y en el seno de las mismas (Tarrow, 1997: 149-161). Todos estos factores cambiantes pueden hacer disminuir los costos de la movilización, al potenciarla, reduciendo así las posibilidades de la represión.

Fue Michael Lipsky uno de los más claros referentes del modelo de Proceso Político. En su estudio, el foco de atención está puesto en la relación que se establece entre el liderazgo de la protesta y su base organizada, las interrelaciones con los medios de comunicación, los grupos objetivos y los terceros partidos. Intentó presentar una perspectiva teórica acerca de la protesta como recurso político. Partió de la convicción que el uso frecuente del mecanismo de la protesta representa un aspecto muy importante para los sectores políticos y sociales más débiles, es decir, aquellos que adolecen de recursos políticos tradicionales y que suelen caracterizarse por una baja eficacia política. Para este intelectual de la Universidad de Wisconsin la actividad de protesta define un tipo de acción orientada hacia la impugnación de políticas y/o condicionamientos, que es llevada adelante para obtener respuestas del sistema político o económico mientras se permanece dentro de él. Una de sus hipótesis más novedosas fue: "El problema de los 'menos poderosos' en la protesta es el de involucrar a 'terceros actores', para que entren en el espacio del debate y los favorezcan." (Lipsky, 1968: 1145). En su visión, los medios de comunicación y las referencias públicas juegan un papel decisivo en la protesta. Es también un proceso que se caracteriza por relaciones recíprocas en las que los dirigentes diseñan estrategias según la percepción que tienen de las necesidades de otros actores. Estos líderes intentan activar las referencias públicas alrededor de los objetivos de la protesta y, al mismo tiempo, procuran mantener el interés y el apoyo de los participantes de la organización que lleva adelante la acción. Los medios de comunicación son extremadamente poderosos cuando se trata de políticas municipales. Son quienes determinan qué información tendrá la mayoría de la gente y sobre qué temas, además de proponer las alternativas que existen para la resolución de estos últimos. Los medios son los que establecen la agenda política, es decir, lo que se discute, y son ellos los que ponen los límites en la protesta, ya que ésta no existe si no es percibida y proyectada. Es una suerte de ecuación: mayor publicidad en espacios más amplios, mayor probabilidad de que la protesta triunfe. (Lipsky, 1968: 1151).

Resumamos la hipótesis explicativa central de Lipsky: en el contexto general de un espacio público donde existen actores poderosos políticamente, que discuten entre sí sin necesitar terceros que los apoyen (por ejemplo: un sindicato discute directamente con la empresa y/o el gobierno) existen grupos más débiles cuyas demandas solo pueden ser satisfechas si logran involucrar a los 
medios y la opinión pública. Estos grupos débiles enfrentan otros conflictos, ya que su fragilidad reside en la falta de una organización estable que cuente con liderazgos fuertes y un presupuesto que les permita tener buen asesoramiento para llevar adelante una acción de lobby. La protesta tiene que ser pensada como un problema de "regateo" (bargaining); por lo tanto, los grupos más débiles tienen poco que ofrecer en un trueque frente a un actor fuerte como las instituciones políticas y económicas. Para graficar esto, Lipsky construye un modelo hipotético: A quiere discutir (regatear) con B. Pero A no tiene nada que B necesite por lo tanto no hay posibilidad de intercambio. A, entonces, intenta crear recursos políticos promoviendo que otros grupos entren en el conflicto. A se organiza para desarrollar una acción contra $B$ respecto de ciertos objetivos. La información referida a estos objetivos se comunica a través de los medios de comunicación $C$, D y E para impactar en $F$, $\mathrm{G}$ y $\mathrm{H}$, que son los referentes públicos (opinión pública) de $\mathrm{B}$. En respuesta a las reacciones de $\mathrm{F}, \mathrm{G}$ y H, o anticipándolas, B responde a las demandas de A (Lipsky, 1968: 1146). Veamos ahora como se produce las respuestas de B a A. Según Lipsky, hay al menos seis tácticas para los destinatarios de la protesta que sirven para satisfacer la demanda de los que se rebelan pero que están orientadas fundamentalmente a satisfacer a los terceros actores: 1) Generar satisfacciones simbólicas (por ejemplo, cortar una cinta inaugurando una obra); esta acción reduce la ansiedad de los actores; 2) Generar satisfacciones materiales aparentando responder a una cuestión general pero respondiendo en realidad a un caso particular; 3) Producir cambios internos de alto impacto; 4) Mostrarse limitados para responder a las demandas, mostrando además que éstas son irracionales o desmedidas; 5 ) Desacreditar a los líderes de la protesta; 6) Posponer las acciones (Lipsky, 1968: 1155-1157).

La conclusión, pues, que podemos alcanzar con Lipsky es que para que la protesta de un actor débil triunfe tiene que interesar a un tercero (los medios y la opinión pública). Es así como puede entrarse en la confrontación con una posición favorable a las metas de la protesta. Ahora bien, esta explicación, como todas las comprendidas dentro del "modelo de Proceso Político", si bien tiene la virtud de devolvernos a un contexto que sitúa en una referencia histórica la actividad de los movimientos sociales y los enmarca dentro de procesos sociales, políticos y económicos compartiendo un mismo tipo de lógica, tiene el problema de que hace depender el éxito de todo movimiento social de las oportunidades que se crean en dicho marco político, independientemente de la capacidad de acción y organización de aquél.

Un dilema de los movimientos sociales: entre la movilización y la organización

Una de las principales disyuntivas que enfrentan los movimientos sociales es la contradicción abierta entre la dinámica de la movilización que les dio vida y la puesta en práctica de formas de organización e institucionalización que puedan permitirles conseguir sus objetivos de manera continuada en el futuro. Los estudios de Claus Offe (1988 y 1992) pueden resultar adecuados para indagar en este dilema. Para encarar esta tarea, el sociólogo y politólogo alemán plantea un modelo por etapas que permita dar cuenta de la evolución de estos nuevos movimientos sociales. Como ocurre con todo modelo teórico, estamos ante un esquema tentativo y generalizador, que no describe la realidad concreta de ningún movimiento social en particular, sino que traza una serie de rasgos que pueden ser comunes a todos. El autor ha tomando como punto de referencia implícito de su estudio la experiencia de los movimientos ecologistas, pacifistas y "radicales" que confluyeron en el 
Partido Verde de Alemania Occidental entre las décadas de 1960 y 1980.

Desde la perspectiva recién aludida, pueden reconocerse tres etapas en los movimientos sociales o sociopolíticos como formas de acción colectiva: a) despegue; b) estancamiento; c) institucionalización. La fase a), la del despegue, comienza en un vacío institucional; sólo se dispone de los derechos ciudadanos a reunirse, comunicarse, protestar, peticionar o manifestar. El movimiento, en general, emerge a partir de un suceso ampliamente divulgado y visible, que desata manifestaciones de opinión y protesta, y que ayuda, por eso, a definir el colectivo de los que real o potencialmente, se ven afectados por él. La ausencia de formas orgánicas y de recursos institucionalizados no se percibe como una desventaja, pues éstas son definidas como innecesarias o perjudiciales pues podrían apropiarse de las energías políticas movilizadas por el movimiento. Como señaló Offe (1992: 277): “El énfasis está abrumadoramente situado en el 'contenido', no en la 'forma'. El estilo del discurso y la acción están caracterizados por la retórica militante, la espontaneidad, la experimentación descentralizada y, con frecuencia, por la confrontación vehemente. La acción no se desencadena de acuerdo con planes, estrategias o decisiones de la dirección, sino por 'provocaciones' percibidas a las que se responde con demandas radicales." La radicalidad de estas demandas se sostiene en que se expresan en un lenguaje absoluto que no deja lugar al gradualismo o al compromiso, sino que insiste en el cumplimiento inmediato de las exigencias; al mismo tiempo, estas exigencias no son elaboradas por intermediarios o a través de un mecanismo de deliberación, representación y cálculo táctico, sino que son expresión plebiscitaria de los valores morales y de los sentimientos de protesta de los que componen el movimiento. Por otra parte, dada la retórica dominante que resalta el valor de la unidad y la falta de un mecanismo elaborado para la toma colectiva de decisiones, no se produce una separación explícita entre los líderes y sus seguidores, entre estos últimos y el público en general y entre grupos discrepantes dentro del movimiento. Las eventuales controversias son saldadas mediante la regla de la unanimidad y todas las distinciones son ignoradas, reprimidas o despojadas de reconocimiento y legitimidad en nombre de las "raíces de la democracia".

La fase b), la del estancamiento, evidencia la impericia que tienen los movimientos sociales para enfrentar la variable "tiempo", dado que en sus demandas ellos no anticipan un proceso extenso de transición, una reforma gradual o una lenta mejora, sino un cambio inmediato y súbito. La simpleza en el proceso de toma de decisiones sólo permite respuestas rápidas sobre la marcha pues cualquier pronóstico teorizador, de planificación a largo plazo o de cálculo de inversión política presupondría una división interna del trabajo entre líderes, seguidores y staff permanente. Por otra parte, los movimientos sociales presentan un horizonte temporal extremadamente restringido pues sus propios recursos pueden ser de naturaleza perecedera. Veamos cada uno de ellos. El primero es el derecho a la protesta: el uso de éste puede hacerse con menos facilidad o a un costo mayor si las élites políticas, jurídicas y económicas lo limitan o redefinen. El segundo es la existencia de sucesos dramáticos y visibles que proporcionen razones para la protesta: una efectiva respuesta de la élite puede convertir a estos sucesos en menos visibles y frecuentes, o absorber las demandas de estos movimientos. El tercero es la movilización espontánea de relevantes segmentos de la población para alzarse en protesta: las motivaciones de protesta espontánea muestran una fuerte tenencia al declive, tanto en caso de triunfo como de fracaso.

Ahora bien, como sostuvo Offe (1992: 282): "Los problemas que plantea un enfriamiento del entusiasmo en el movimiento son especialmente difíciles de resolver bajo unas condiciones en las 
que están ausentes las tres características esenciales de organización formal: el papel de líder, el papel de miembro y los procedimientos establecidos para hacer frente a conflictos y divisiones." Se quiere superar las deficiencias que resultan de la experiencia de continuidad precaria de estos movimientos, dado los cambios abruptos en los niveles de apoyo y actividad. Para eso, ahora la clave estará en la comunicación interna y en la formalización orgánica. La tendencia es a adoptar los rasgos básicos de la organización formal: 1) la adquisición de los fondos y los conocimientos legales necesarios para detentar la representación legal de los activistas procesados por presuntas violaciones de los derechos de otros o por desafiar las prácticas y acuerdos vigentes a través del sistema judicial; 2) el inicio de la formalización de los papeles de miembro y de la diferenciación común entre, por un lado, miembros y no miembros y, por otro, miembros y líderes; 3) realización de conferencias, reuniones regulares y otras formas de comunicación interna horizontal a efectos de debate y reconciliación de divisiones internas sobre cuestiones ideológicas y tácticas entre líderes del movimiento. Producido este fenómeno, según el sociólogo alemán, una mutación se ha experimentado: "Una vez realizadas estas tres manifestaciones, el movimiento ha avanzado un largo trecho desde su fase inicial de espontaneidad e informalidad, alcanzando un cierto grado de madurez orgánica. El centro de la actividad se ha trasladado desde las demandas esenciales y la actividad de protesta hasta la preocupación formal y reflexiva respecto a las condiciones bajo las cuales el movimiento puede obtener cierto grado de permanencia y ampliación del horizonte temporal." (Offe, 1992: 283-284).

Finalmente, la tercera fase que enfrentan los movimientos sociales, la c), es la de la institucionalización. Esta es la más reveladora para nuestro propósito, el de afrontar el dilema que se abre a todos los movimientos sociales: movilización o institucionalización. En un sector del movimiento comienza a pesar el temor de que cualquier paso hacia la formalización podría involucrar un peligro de burocratización, centralización, alienación y/o desradicalización, prefiriéndose en cambio la forma espontánea o localista de protesta, amparada en una vaga red de iniciativas independientes. En oposición a esta fracción, surge otra que aboga por una conversión gradual del movimiento hacia formas institucionales de "política normal" (competencia con los partidos, participación en las elecciones, representación parlamentaria, formación de alianzas y coaliciones con fuerzas políticas rivales u ocupación de posiciones en el gobierno). El hecho de entrar en los canales institucionales oficiales de participación y representación política ofrece oportunidades que ninguna otra forma concebible de actividad política podría igualar. El uso de las instituciones políticas de la democracia representativa liberal aparecería, entonces, como una estrategia racional que permitiría la más plena y efectiva utilización de los recursos del movimiento.

La institucionalización política de los movimientos sociales reportaría una serie de ventajas relativas originadas en diversas fuentes. Una de ellas son las provenientes de los beneficios obtenidos de la formación de alianzas: se espera que numerosas cuestiones individuales de los movimientos se reforzarían mutuamente a partir de la mancomunidad de sus respectivos soportes electorales, neutralizando así los altibajos de los ciclos de protesta individual. Existen otros beneficios, los obtenidos de una extracción de apoyo más plena: un movimiento que se convierte en una organización formal pasa a disponer de una importante categoría adicional de recursos, que es el compromiso por parte de los miembros de pagar unas cuotas. Cuando el movimiento se transforma en partido, es aún mayor la capacidad de absorber recursos, pues permite la derivación de los de aquellos que 
no están dispuestos a actuar o pagar, sino sólo a votar. Asimismo, están los beneficios obtenidos del estatuto especial de los partidos políticos en las grandes democracias burguesas occidentales. Offe (1988 y 1992) los analizó para el caso de Alemania Occidental en los años ochenta, encontrando la tendencia a otorgar a los partidos una serie de privilegios especiales que operaban como tentación para los nuevos movimientos sociales. Por ejemplo, las subvenciones que se concedían a todos los partidos que superasen un mínimo piso electoral (haciéndolos así relativamente independientes de los ingresos que no procedían de las cuotas de sus miembros o de las contribuciones privadas a las campañas) o el tiempo disponible que se les concedía a todos los partidos en las emisoras públicas de radio y televisión. Por último, estaban los beneficios obtenidos de la lógica de la competencia de los partidos: son los que provienen del aprovechamiento que todo partido hace de las ventajas de los otros al forzarlos, a través de la competencia electoral-parlamentaria, a diseñar de nuevo su propio producto (es decir, su plataforma o programa). De esta manera, el partido puede producir un cambio indirecto del discurso y el conflicto político.

Sin embargo, estas cuatro ventajas que los movimientos sociales pueden obtener en la transición hacia una institucionalización política no alcanzan a convencer a todos los componentes de esos movimientos de lo beneficioso que resultaría dicha transición. Así, se ha detectado en casi todos los movimientos sociales el modo en que surgen sectores que plantean un argumento antiinstitucional. Desde éste se alertan sobre las desventajas que conllevan la institucionalización o conversión de los movimientos en partidos. Estos inconvenientes se expresarían en los riesgos a la pérdida de identidad, autonomía y de carácter diferenciador de cada uno de los movimientos sociales que confluyen en un partido. Estos sectores antiorganizacionales dirigen sus advertencias hacia tres tópicos: a) que la mancomunidad de diversos tipos de apoyo (actuación, pago de cuotas, votación) podría conducir a una relativa pérdida de influencia del núcleo activista del movimiento; b) que los recursos y privilegios asociados a la forma de partido político corromperán a los representantes y comprometerán las demandas del movimiento; c) que es probable que la lógica de asimilación inherente a los modos institucionales de la competencia electoral actúe en ambos sentidos, extendiéndose así a la representación parlamentaria del movimiento al menos en la misma medida en que el movimiento es capaz de persuadir a sus competidores.

Estos planteos "antiinstitucionalistas" se han alimentado teóricamente, en parte, con la línea argumental delineada por la ley de hierro de la oligarquía del sociólogo alemán Robert Michels, en su ya clásico libro Los partidos políticos (2008). Inspirados en estas posiciones, varios autores tendieron a comprender a la organización como algo enfrentado a problemas irreversibles: cooptación, oligarquización, desmovilización y destrucción final del movimiento. En este sentido, podemos destacar a Michael Lipsky (1968), junto a otros estudiosos del tema (como los sociólogos, politólogos y activistas norteamericanos Frances Fox Piven y Richard A. Cloward, 1977). Desde este punto de vista se identificó a la organización formal como la causa directa del deterioro y posterior defunción de los movimientos sociales. La explicación es que mientras exista protesta callejera, habrá disrupción social y existirá una amenaza real al orden social establecido. Es decir, habrá un temor concreto de las élites a que una pequeña revuelta llegue a trascender a otros sectores y pueda llegar a convertirse en una protesta popular incontrolable. Según Lipsky, si las energías de los miembros de la base del movimiento, que son dedicadas a la protesta, se recanalizan para crear una estructura organizacional del movimiento, inevitablemente se pierde el único recurso 
que los movimientos sociales tienen a su alcance como instrumento de negociación: la amenaza de insurrección y de revertir el orden social. Una vez perdido el único mecanismo de negociación eficaz, el movimiento queda descapitalizado para tranzar con las élites. Y éstas pueden darse el lujo de ignorar las peticiones de los movimientos sin costos aparentes. Así, mientras un sector de los movimientos sociales se opuso al curso hacia la institucionalización o la conversión en partido, otro sector, finalmente más numeroso y crecientemente hegemónico, tendió a presionar por impulsar esta transición, alertando sobre las oportunidades o ventajas que se pierden si se decide abortar este proceso.

Detrás de este debate entre "movilización" y "organización", subyació una disputa que recorrió desde siempre a las concepciones teórico-políticas que apuntaron y reflexionaron acerca del cambio social. Por ejemplo, es inevitable remitir a la histórica polémica que sacudió, entre fines del siglo XIX y principios del XX, al movimiento socialdemócrata internacional. En efecto, en las discusiones entre Edouard Bernstein, Rosa Luxemburgo, Karl Kautsky y Vladimir I. Lenin, se hayan presentes muchos de los elementos de controversia que aquí hemos referenciado.

\section{Conclusiones}

El recorrido por los diversos aportes, teorías y modelos explicativos de la acción colectiva y los movimientos sociales, muestra la creciente complejización del análisis y de los resultados alcanzados. Lo que no es sino una evidencia más de los avances logrados por la teoría sociológica, en busca de adecuar su capacidad explicativa frente a los nuevos fenómenos sociales de protesta. Frente a las primeras interpretaciones, que buscaban una asociación directa entre las tensiones estructurales en una sociedad y la movilización de la protesta, se avanzó con un modelo multifactorial que analítica y sucesivamente hilvanaba los siguientes pasos: a) tensiones; b) malestar, disidencia, descontento y privación; c) recursos internos (redes, organización) y recursos externos (oportunidades políticas); d) acción colectiva (movilización de la protesta).

\section{Referencias Bibliográficas}

Blanco, A. (2006). Razón y modernidad. Gino Germani y la sociología en la Argentina. Buenos Aires. Siglo veintiuno editores.

Bonamusa Miralles, M. (1994). Movimientos sociales: organización y estructura de oportunidad política. Revista Análisis Político, 23: 54-66.

Germani, G. (1962). Política y sociedad en una época de transición. Buenos Aires. Paidós.

Gurr, T. (1970). Why Men Rebel. Princeton. Princeton University Press.

Hobsbawm, E. J. (1968). Rebeldes primitivos. Barcelona. Ariel Quincenal.

Jenkins, J. C. (1994). La teoría de la movilización de recursos y el estudio de los movimientos 
sociales. Revista Zona Abierta 69: 4-49.

Jorrat, J. R. \& Sautu, R. (comps.) (1992). Después de Germani. Exploraciones sobre estructura social de la Argentina. Buenos Aires. Paidós.

Kaye, H. (1989). Los historiadores marxistas británicos. Zaragoza. Universidad de Zaragoza.

Kornhauser, W. (1959). The Politics of Mass Society. Glencoe, Illinois. The Free Press.

Le Bon, G. (2005). Psicología de las masas. Madrid. Morata.

Lefebvre, G. (1986). El gran pánico de 1789. La Revolución Francesa y los campesinos. Barcelona. Paidós.

Lipsky, M. (1968). Protest as a Political Resource. Revista The American Political Science Review 62, 4: 1144-1158.

Melucci, A. (1988). Las teorías de los movimientos sociales. En Cohen, J., Touraine, A., Melucci, A. \& Jenkins, J. C. (comps.). Teoría de los movimientos sociales. Costa Rica. FLACSO, Cuadernos de Ciencias Sociales.

Merton, R. (1957). Social Theory and Social Structure. Glencoe, Illinois. The Free Press.

Michels, R. (2008). Los partidos políticos: un estudio sociológico de las tendencias oligárquicas de la democracia moderna. Buenos Aires. Amorrortu.

Moore, Jr., B. (1965). Political Power and Social Theory: Seven Studies. New York. Harper \& Row.

Oberschall, A. (1973). Social Conflict and Social Movements. Englewood Cliffs. Prentice Hall.

Offe, C. (1988). Partidos políticos y nuevos movimientos sociales. Madrid. Sistema. (1992). La gestión política. Madrid. Ministerio de Trabajo.

Olson, M. (1965). The Logic of Collective Action. Cambridge. Harvard University Press.

Parsons, T. (1966). El sistema social. Madrid. Revista de Occidente.

Pérez Ledesma, M. (1994). 'Cuando lleguen los días de cólera' (Movimientos sociales, teoría e historia). Revista Zona Abierta 69: 51-120.

Piven, F. \& Cloward, R. (1977). Poor People's Movements: Why They Succeed. How They Fail. New 
York. Pantheon Books.

Raschke, J. (1994). Sobre el concepto de movimiento social. Revista Zona Abierta 69: 121-134.

Revilla Blanco, M. (1994). El concepto de movimiento social: acción, identidad y sentido. Revista Zona Abierta 69: 181-213.

Rudé, G. (1971). La multitud en la historia: estudio de los disturbios populares en Francia e Inglaterra, 1730-1848. Buenos Aires. Siglo veintiuno argentina editores.

Shorter, E. \& Tilly, Ch. (1985). Las huelgas en Francia, 1830-1968. Madrid. Ministerio de Trabajo y Seguridad Social.

Skocpol, T. (1984). Los estados y las revoluciones sociales. Un análisis comparativo de Francia, Rusia y China. México. FCE.

Smelser, N. (1989). Teoría del comportamiento colectivo. México. FCE.

Tarde, G. (2006). Monadología y sociología. Buenos Aires. Cactus.

Tarrow, S. (1997). El poder en movimiento. Madrid. Alianza.

Thompson, E. P. (1991). Costumbres en común. Barcelona. Crítica.

Tilly, Ch. (1978). From Mobilization to Revolution. New York. McGraw-Hill.

-------- (1995). Popular Contention in Great Britain, 1758-1834. Cambridge. Harvard University Press.

Tilly, Ch. \& Wood, L. (2009). Los movimientos sociales, 1768-2008. Desde sus orígenes a Facebook (segunda edición). Barcelona. Crítica. 